\title{
Therapeutic effect of antisecretory factor-rich egg yolk on the late phases of 2,4,6-trinitrobenzenesulphonic acid colitis in mice
}

\author{
Josep Mañé ${ }^{1,2 *} \dagger$, Violeta Lorén ${ }^{1,2} \dagger$, Elisabet Pedrosa ${ }^{1,2}$, Isabel Ojanguren ${ }^{3}$, Eugeni Domènech ${ }^{2,4}$, \\ Miquel A. Gassull ${ }^{5}$ and Eduard Cabré ${ }^{2,4}$ \\ ${ }^{1}$ Gastroenterology and Nutrition Research Unit, 'Germans Trias i Pujol' Research Institute in Health Sciences, Carretera del \\ Canyet s/n, 08916 Badalona, Catalonia, Spain \\ ${ }^{2}$ Centro de Investigación en Red de Enfermedades Hepáticas y Digestivas (CIBERehd), O8036 Barcelona, Spain \\ ${ }^{3}$ Department of Pathology, Hospital Universitari 'Germans Trias i Pujol', 08916 Badalona, Catalonia, Spain \\ ${ }^{4}$ Department of Gastroenterology, Hospital Universitari 'Germans Trias i Pujol', 08916 Badalona, Catalonia, Spain \\ 5 'Germans Trias i Pujol' Research Institute in Health Sciences, 08916 Badalona, Catalonia, Spain
}

(Received 4 August 2010 - Revised 9 March 2011 - Accepted 16 March 2011 - First published online 1 July 2011)

\section{Abstract}

Antisecretory factor (AF) is expressed in all tissues of mammals, inhibits intestinal hypersecretion and has anti-inflammatory properties as well. Endogenous AF synthesis may be stimulated by feeding hydrothermally processed cereals. Alternatively, freeze-dried egg yolk can be used as a source of exogenous AF. Several reports have suggested that AF from freeze-dried egg yolk may be useful in inflammatory bowel disease. We assessed the effect of freeze-dried, AF-rich egg yolk intake on 2,4,6-trinitrobenzenesulphonic acid (TNBS) colitis. Balb/c mice were randomised to receive (1) AF in sterile drinking-water ( $4 \mathrm{~g} / 1, n 38)$ and (2) sterile drinking-water alone (vehicle, $n$ 38) from TNBS or saline administration onwards. Different subsets of mice were killed at weeks $1-3$ after TNBS or saline administration. Macroscopic and microscopic damage was assessed in colonic specimens. Eicosanoid and cytokine production was evaluated in supernatants of $24 \mathrm{~h}-\mathrm{incu}-$ bated colonic explants. Myeloperoxidase activity was measured in frozen colonic samples, while apoptosis was assessed in paraffined samples by the in situ oligoligation method. AF-treated mice showed a milder colonic damage compared with the vehicle group, which became statistically significant at week 3. This was accompanied by decreased IL-2, IL-1 and leukotriene $\mathrm{B}_{4}$ production at weeks 2 and 3 , as well as increased interferon- $\gamma$ at week 1 , in AF-treated mice compared with vehicle-treated mice. AF-treated mice had significantly increased counts of apoptotic cells in the lamina propria at weeks 1 and 2 post-TNBS. In conclusion, the administration of AF-rich egg yolk has a therapeutic effect in the late phases of TNBS colitis in Balb/c mice.

Key words: Antisecretory factor: Trinitrobenzenesulphonic acid: Cytokines: Eicosanoids: Apoptosis

Antisecretory factor (AF) is a $41 \mathrm{kDa}$ hypothalamic protein that exerts an inhibitory effect on intestinal secretion, as shown in several experimental models of diarrhoea in rats and pigs $^{(1,2)}$. Thus, as few as $10^{-11}$ to $10^{-12} \mathrm{~mol} / \mathrm{l}$ of recombinant $\mathrm{AF}$, added to either the mucosal or serosal side, is enough to revert intestinal hypersecretion induced by cholera toxin in vivo ${ }^{(1)}$. Recombinant $\mathrm{AF}$ also inhibits the inflammatory response induced by Clostridium difficile toxin A in rat jejunal loops ${ }^{(2)}$. In fact, both enterotoxins and dietary supplementation with hydrothermally processed cereals (HPC) stimulate endogenous AF synthesis, and suppress the hippocampal $\gamma$-aminobutyric acid (A)-mediated synaptic transmission in rats, mimicking the effect of exogenously administered $\mathrm{AF}^{(3)}$. Experimental data also show anti-inflammatory properties of $\mathrm{AF}$ based on the modulation of lymphocyte proliferation in vitro. AF is expressed by antigen-presenting cells and B-cells in the gut-associated lymphoid tissue, and it may regulate T-cell activity through mechanisms involving monocyte/macrophage/microglia cells ${ }^{(4)}$. These data support a gut-brain crosstalk that participates in the homeostasis of intestinal secretion and inflammation.

Patients with chronic inflammatory bowel disorders and secretory diarrhoea may benefit from an AF-inducing diet (active treatment). An HPC-induced increase in endogenous

Abbreviations: AF, antisecretory factor; HPC, hydrothermally processed cereals; IFN, interferon; IQR, interquartile range; LTB 4 , leukotriene $\mathrm{B}_{4}$; TNBS, trinitrobenzene sulphonic acid.

*Corresponding author: J. Mañé, fax +3493 4978654, email jmanye.igtp.germanstrias@gencat.cat

†These two authors contributed equally to the present study. 
AF has been associated with clinical improvement in ulcerative colitis, Crohn's disease and hormone-mediated secretory diarrhoea $^{(5,6)}$. After 2 weeks of supplementary HPC therapy, AF plasma levels may increase $10-$ fold $^{(5,6)}$. However, Crohn's disease patients with major small-bowel resections were unable to significantly raise endogenous $\mathrm{AF}$ production ${ }^{(7)}$, and HPC may also facilitate intestinal occlusion in patients with bowel strictures. For these reasons, some clinical trials have used freeze-dried egg yolk as a source of AF (passive treatment $)^{(8)}$. In these pilot studies, freeze-dried, AF-rich egg-yolk improved clinical symptoms in ulcerative colitis patients and reverted hypersecretory diarrhoea of diverse aetiologies $^{(6,9)}$. Moreover, successful outcome of a patient with severe and refractory Crohn's disease, who was treated with AF-rich egg-yolk drinks, has been reported ${ }^{(10)}$. AF-rich egg-yolk treatment is unable to increase AF plasma levels as effectively as the active treatment with HPC does ${ }^{(6,10)}$. In spite of this, $\mathrm{AF}$ passive treatment is associated with a significant decrease in several inflammatory parameters and histological recovery in ulcerative colitis and Crohn's disease $^{(9,10)}$. However, the small sample size, the heterogeneity in concomitant drug therapy and the difficulties in obtaining intestinal samples make these studies inconclusive.

The aim of the present study is to assess the effect of freezedried, AF-rich egg yolk intake on the outcome and intestinal damage in a Crohn's disease-like murine model (trinitrobenzene sulphonic acid (TNBS)-induced colitis). TNBS colitis is a common experimental model for the study of new therapeutic approaches as well as dietary supplementation in intestinal inflammation. TNBS develops a delayed hypersensitivity colonic response to allergens that triggers an early acute non-specific inflammatory process with large numbers of neutrophil, and eosinophil polymorphonuclear leucocytes in the colonic mucosa, followed by a chronic inflammatory phenotype with predominance of T-cells later on the colitis course $^{(11,12)}$. In addition to macroscopic and microscopic damage, we evaluated tissue markers of either acute or chronic inflammation, including myeloperoxidase activity, eicosanoid and cytokine production. Also, cell apoptosis was assessed, as it has been reported that Crohn's disease patients exhibit intestinal lymphocytes that are resistant to apoptosis, and increasing apoptosis on the basis of most treatments for both human and experimental intestinal inflammation $^{(13-15)}$.

\section{Materials and methods}

\section{Mice and maintenance conditions}

Female Balb/c mice, 8 weeks old, with a body weight of 20-22 g (Criffa Laboratories, Barcelona, Spain) were housed in wire drop-bottom cages at a constant temperature of $22^{\circ} \mathrm{C}$, with a $12 \mathrm{~h}$ light $-12 \mathrm{~h}$ dark cycle, under specific pathogenfree conditions. Both drinking-water and the AIN-93-based chow diet were sterilised (Harlam Ibérica, Barcelona, Spain) and were supplied ad libitum. Food and water intake, and the body weight of animals were periodically evaluated throughout the experiment. The study was carried out in agreement with the rules of the Guide for the Care and Use of Laboratory Animals, and under the control and management of the Ethical Committee of Animal Experimentation of the 'Germans Trias i Pujol' Research Institute in Health Sciences

\section{Experimental design}

A total of seventy-six mice were randomised into two groups: (1) AF group, including animals that were fed freeze-dried, AF-rich egg yolk (provided by Nestlé Healthcare Nutrition, Barcelona, Spain) dissolved in sterile tap water $(4 \mathrm{mg} / \mathrm{ml})$ and (2) vehicle group that included mice receiving sterile tap water alone. The AF activity of egg yolk provided by the manufacturer was assessed by an in vivo rat bioassay ${ }^{(8)}$ and was found to be $250 \mathrm{mg} / \mathrm{cm}$ of jejunal loop. The $4 \mathrm{mg} / \mathrm{ml}$ dose was chosen from that used in a few studies of Crohn's disease, which have been reported as $8 \mathrm{~g} / \mathrm{d}$ of AF-rich egg yolk, for a $70 \mathrm{~kg}$ subject ${ }^{(10)}$. We extrapolated this dose to the average weight of mice, adjusting for an approximately 12fold increased metabolic rate - based on the concept of nutrient density ${ }^{(16)}$ - and their average fluid intake (approximately $6 \mathrm{ml} / \mathrm{d}$ ) as well. Treatments were administered daily as drinking-water from the first day after colitis induction until killing. TNBS colitis was induced in thirty mice per group, while a sham colitis was induced in the remaining sixteen animals (controls). Killing was performed at weeks 1-3 after colitis induction by cervical dislocation under anaesthesia with isofluorane in different subsets of mice and colonic samples were obtained at that time. Eicosanoid and cytokine production was assessed in supernatants of $24 \mathrm{~h}$-incubated colonic explants immediately after killing. Tissue myeloperoxidase activity was measured in frozen colonic samples, while apoptosis assessment and histological examination were performed in paraffined colonic samples as described below.

\section{Trinitrobenzenesulphonic acid colitis}

Experimental colitis was induced in mice, slightly anaesthetised (Fluothane; Zeneca, Macclesfield, Cheshire, UK), by the intrarectal instillation of $0.1 \mathrm{ml}$ of a mixture of TNBS (SigmaAldrich Química, Madrid, Spain) dissolved in 50\% ethanol $(\mathrm{v} / \mathrm{v})$, at a dose of $50 \mathrm{mg} / \mathrm{kg}$ body weight ${ }^{(17)}$. Then, mice were kept in a vertical position for $30 \mathrm{~s}$. Control animals were induced a sham colitis by the intrarectal administration of $0.1 \mathrm{ml}$ of $0.9 \%$ saline.

\section{Assessment of macroscopic damage}

The colonic weight:length ratio was recorded after killing. Macroscopic colonic damage was assessed taking into account the presence and severity of adhesions (0-2), and strictures $(0-2)^{(17)}$.

\section{Histological examination}

Entire colonic samples arranged in Swiss roll for the histological study were processed by routine techniques. Sections 
( $5 \mu \mathrm{m}$ thick) were stained with haematoxylin and eosin and coded for blind examination. A previously validated score was used to evaluate the degree of colonic injury ${ }^{(17)}$. This score grades from 0 to 12 as the addition of six criteria: mucosal ulceration $(0-2)$; epithelial hyperplasia $(0-2)$; mononuclear cell (0-2) and neutrophilic infiltrate $(0-2)$ in the lamina propria; presence of atrophic crypts $(0-2)$; necrosis $(0-2)$. The incidence of serosal involvement was also evaluated.

\section{Tissue culture}

One of the colonic sections obtained after killing was washed with PBS and seeded in duplicate in twenty-four-well tissue culture plates (Corning, New York, NY, USA) with Roswell Park Memorial Institute-1640 medium (Gibco, Gaithersburg, MD, USA) supplemented with L-glutamine ( $2 \mathrm{mmol} / \mathrm{l}$; SigmaAldrich), $10 \%$ fetal calf serum (Gibco), penicillin $\left(6 \times 10^{4} \mu \mathrm{g} / \mathrm{l}\right)$ and streptomycin $\left(10^{5} \mu \mathrm{g} / \mathrm{l}\right)$. Following a $24 \mathrm{~h}$ incubation period under $5 \% \mathrm{CO}_{2}$ and $37^{\circ} \mathrm{C}$ humidified atmosphere, all supernatants were harvested and stored at $-80^{\circ} \mathrm{C}$ until assayed.

\section{$P G E_{2}$ and leukotriene $B_{4}$ assay}

Eicosanoid concentrations were measured in culture supernatants by commercial $\mathrm{PGE}_{2}$ and leukotriene $\mathrm{B}_{4}\left(\mathrm{LTB}_{4}\right)$ ELISA (Cayman Chemical, Ann Arbor, MI, USA) following the manufacturer's technical specifications. Optical densities were measured with Kinetic-QCL (Bio-Whittaker, Lab Extreme, Kent City, MI, USA) at a wavelength of $405 \mathrm{~nm}$. Data were analysed against the linear portion of a standard curve and normalised to the weight of the colonic explant.

\section{Cytokine production}

Concentrations of IL-1, IL-2, IL-4, IL-5, IL-6, IL-10, IL-12p70, TNF- $\alpha$ and interferon (IFN)- $\gamma$ were measured by commercial multiple sandwich ELISA (SearchLight Mouse Cytokine Array; Pierce, Rockford, IL, USA) in culture supernatants at a dilution of 1:50 following the manufacturer's specifications. Chemiluminescent signal was detected with a cooled charge-coupled device camera (BioImaging Systems, Upland, CA, USA). The amount of signal produced was proportional to the amount of each cytokine in the original standard or sample. Data are expressed as ng/l of cytokine per mg of colonic explants.

\section{Myeloperoxidase activity}

Myeloperoxidase activity was measured in homogenised colonic samples, by a photometric method using 3,3',5,5'tetramethylbenzidine as a substrate following a method described previously ${ }^{(17)}$.

\section{Apoptosis detection (ISOL method)}

Colonic paraffin-embedded samples were placed on polyL-lysine-coated microscope slides. An in situ oligoligation assay was performed according to the manufacturer's instructions (ApopTag ${ }^{\circledR}$ Peroxidase In Situ OligoLigation; Chemicon International, Billerica, MA, USA). In short, endogenous peroxidase activity was blocked by incubating slides in 3\% $\mathrm{H}_{2} \mathrm{O}_{2}$ in PBS. Then, sections were incubated with proteinase $\mathrm{K}$ and kept on equilibration buffer. Then, specimens were incubated with $\mathrm{T}_{4}$ DNA ligase and biotin-labelled oligonucleotides. Detection was subsequently performed by binding a streptavidin-peroxidase conjugate to biotin. Localisation of apoptotic cells was performed by 3,3'-diaminobenzidine tetrahydrochloride substrate deposition and blindly assessed with light microscopy. The slides were counterstained with haematoxylin. Counts were carried out at a constant magnification $(600 \times)$ assessing fifteen to twenty representative fields of the entire colon, assessing epithelial cells, intra-epithelial lymphocytes and lamina propria lymphocytes separately. Sections incubated without $\mathrm{T}_{4}$ DNA ligase were used as negative controls, whereas rat mammary gland slides were used as positive ones.

\section{Statistical analysis}

Results are expressed as means with their standard errors or medians plus interquartile ranges (IQR), as required. Comparison of qualitative variables between groups was performed using the $\chi^{2}$ test corrected to Fisher's test, while ANOVA and Mann-Whitney $U$ tests were used for comparison of quantitative variables, as required. Statistical analysis was carried out with the SPSS 12.0 package (SPSS, Inc., Chicago, IL, USA). A $P$ value $\leq 0.05$ was considered significant.

\section{Results}

Spontaneous mortality was the same ( $n$ 6) in both therapeutic groups, all fatalities occurring during the first week after TNBS administration. No less than seven mice per time point and group were available for analysis. No difference in water intake was observed between the experimental groups, with a daily average of $5 \mathrm{ml}$. During the time course of colitis, body weight showed a significant decrease compared with sham colitis mice at week 1 post-TNBS (Fig. 1). The animals were killed 7, 14 and $21 \mathrm{~d}$ after TNBS administration or $21 \mathrm{~d}$ after saline instillation (sham colitis). A progressive decrease in the severity of macroscopic intestinal damage (i.e. adherences and strictures) during the time course of TNBS colitis in both study groups was observed (Table 1). A significantly higher weight:length ratio at the third week post-TNBS colitis induction was observed in vehicle-treated mice compared with AF-treated mice. In addition, only two vehicle-treated mice showed macroscopic blood in the stool during the week 1 post-TNBS.

The histological score (Fig. 2(a)) was significantly higher in vehicle-treated mice compared with those with sham colitis $(P \leq 0.05)$. However, these differences were not seen from week 2 onwards in AF-treated animals. In fact, mice treated with AF showed a trend towards a milder colonic damage compared with the vehicle group, which became statistically significant at week 3. Moreover, vehicle-treated mice with 


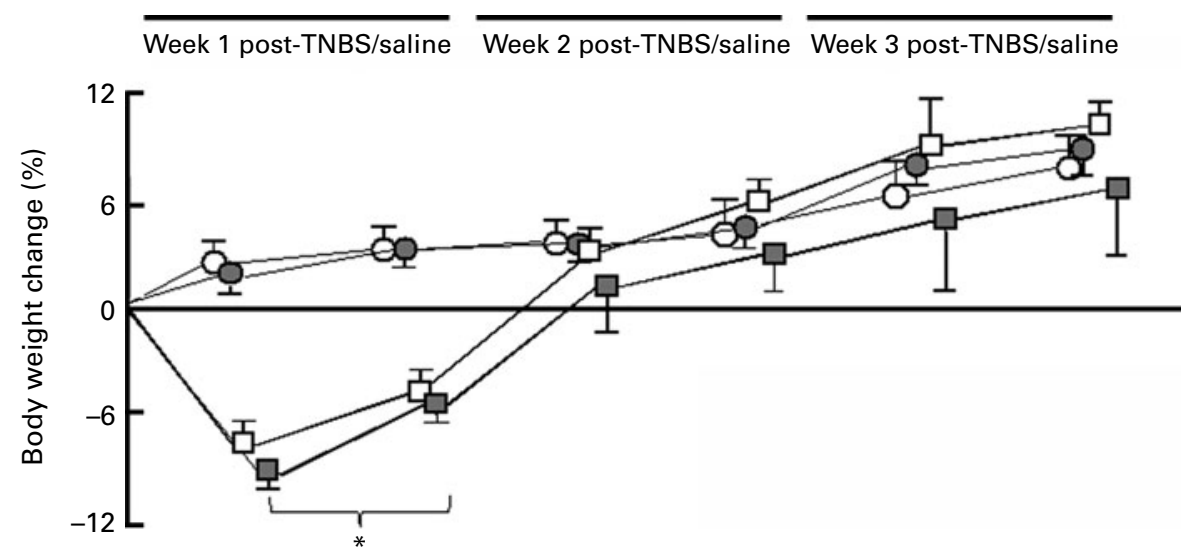

Fig. 1. Time course of the body-weight change (\%) in the four groups of mice studied. Values are means, with their standard errors represented by vertical bars. * Mean values were significantly different from those of sham $(P<0.05)$. -0 -, Sham colitis/vehicle; -0 -, sham colitis/antisecretory factor (AF); $-\square-$, trinitrobenzenesulphonic acid (TNBS) colitis/vehicle; $\_-$, TNBS colitis/AF.

colitis showed a higher incidence of serosal involvement at week 1 compared with those treated with $\mathrm{AF}(80 \% v .20 \%$, respectively; $P=0 \cdot 012$ ).

No significant differences regarding the production of most cytokines were observed in the first week after TNBS administration between the two study groups, except for IFN- $\boldsymbol{\gamma}$, which was higher in the AF group compared with the vehicle group (Table 2). On the other hand, significant decreases in the production of IL- 2 at week 2 and IL- 1 at week 3 were observed in AF-treated mice compared with those treated with vehicle.

$\mathrm{LTB}_{4}$ production increased in vehicle-treated mice but not in AF-treated ones. Again, this was particularly evident at weeks 2 and 3 (Fig. 2(b)). This was not the case for $\mathrm{PGE}_{2}$ production, which significantly increased in both groups compared with baseline values with only a small but significant difference between AF and vehicle animals at week 2 (Fig. 2(c)).

Myeloperoxidase activity increased after colitis induction in both AF- and vehicle-treated mice, and remained significantly elevated until the second week post-TNBS, returning to baseline values at the third week (Table 1).

In comparison with sham mice, animals treated with AF-rich egg yolk showed significantly increased counts of apoptotic mononuclear cells in the lamina propria both at week 1 (0.5 (IQR 0.4-1.8) v. 0 (IQR $0-0.2) ; P<0.05)$ and week 2 (0.5 (IQR $0.4-4.4)$ v. 0 (IQR $0-0.2) ; P<0.05)$ after colitis induction, with no changes in the vehicle group. Also, no differences in apoptotic cell counts were found for epithelial cells and intra-epithelial lymphocytes in both AF- and vehicle-treated mice.

\section{Discussion}

The present study suggests that AF may have a beneficial effect on the long-term outcome of TNBS colitis as shown by a less severe histological score and a lower colonic weight: length ratio 3 weeks after inducing colonic injury. In addition, AF-treated animals showed a significant decrease in the

Table 1. Macroscopic features and myeloperoxidase activity in the colon of the different groups of mice

(Median values, interquartile ranges (IQR) or mean values with their standard errors)

\begin{tabular}{|c|c|c|c|c|c|c|c|c|c|}
\hline & \multirow[b]{3}{*}{ Treatment } & \multicolumn{6}{|c|}{ TNBS colitis } & \multirow{2}{*}{\multicolumn{2}{|c|}{$\begin{array}{c}\text { Sham colitis } \\
\text { Week } 3\end{array}$}} \\
\hline & & \multicolumn{2}{|c|}{ Week 1} & \multicolumn{2}{|c|}{ Week 2} & \multicolumn{2}{|c|}{ Week 3} & & \\
\hline & & Median & IQR & Median & IQR & Median & IQR & Median & IQR \\
\hline \multirow{2}{*}{ Adherences } & AF & $1.3^{*}$ & $0.7-2.0$ & 1.3 & $0.7-2.0$ & $0.7^{*}$ & $0.5-2.0$ & 0 & \\
\hline & Vehicle & $2 \cdot 0^{*}$ & $1.5-2.0$ & $1 \cdot 3^{*}$ & $1 \cdot 3-2 \cdot 0$ & $1 \cdot 3^{*}$ & $0.8-1.3$ & 0 & \\
\hline \multirow[t]{2}{*}{ Strictures } & $\mathrm{AF}$ & $1.3^{*}$ & $0.2-2.0$ & 0 & 0 & 0 & & 0 & \\
\hline & Vehicle & $2 \cdot 0^{\star}$ & $0.5-2.0$ & 0 & 0 & 0 & & 0 & \\
\hline \multirow[t]{2}{*}{ Weight:length ratio $(\mathrm{mg} / \mathrm{cm})$} & $\mathrm{AF}$ & $27^{\star}$ & $26-42$ & 26 & $21-33$ & $19 \dagger$ & $16-23$ & 19 & $14-22$ \\
\hline & Vehicle & $39^{*}$ & $23-55$ & $27^{*}$ & $23-34$ & 23 & $22-26$ & 20 & $16-23$ \\
\hline \multicolumn{10}{|c|}{ Myeloperoxidase activity (U/mg) } \\
\hline & Mean & \multicolumn{2}{|l|}{$\begin{array}{l}0.4^{*} \\
0.2\end{array}$} & \multicolumn{2}{|l|}{$0.2^{*}$} & \multicolumn{2}{|l|}{0} & \multicolumn{2}{|l|}{0} \\
\hline & $\begin{array}{c}\text { SEM } \\
\text { Vehicle }\end{array}$ & & \multicolumn{2}{|l|}{0.1} & \multicolumn{2}{|l|}{0} & \multicolumn{2}{|l|}{0} \\
\hline & Mean & \multicolumn{2}{|l|}{$0.3^{*}$} & \multicolumn{2}{|l|}{0.2} & \multicolumn{2}{|l|}{0} & \multicolumn{2}{|l|}{0} \\
\hline & SEM & \multicolumn{2}{|l|}{0.1} & \multicolumn{2}{|l|}{0.1} & \multicolumn{2}{|l|}{0} & \multicolumn{2}{|l|}{0} \\
\hline
\end{tabular}

TNBS, trinitrobenzenesulphonic acid; AF, antisecretory factor.

${ }^{*}$ Values were significantly different from those of sham $(P \leq 0.05)$.

$\dagger$ Values tended to be significantly different from those of vehicle $(P=0.049)$. 

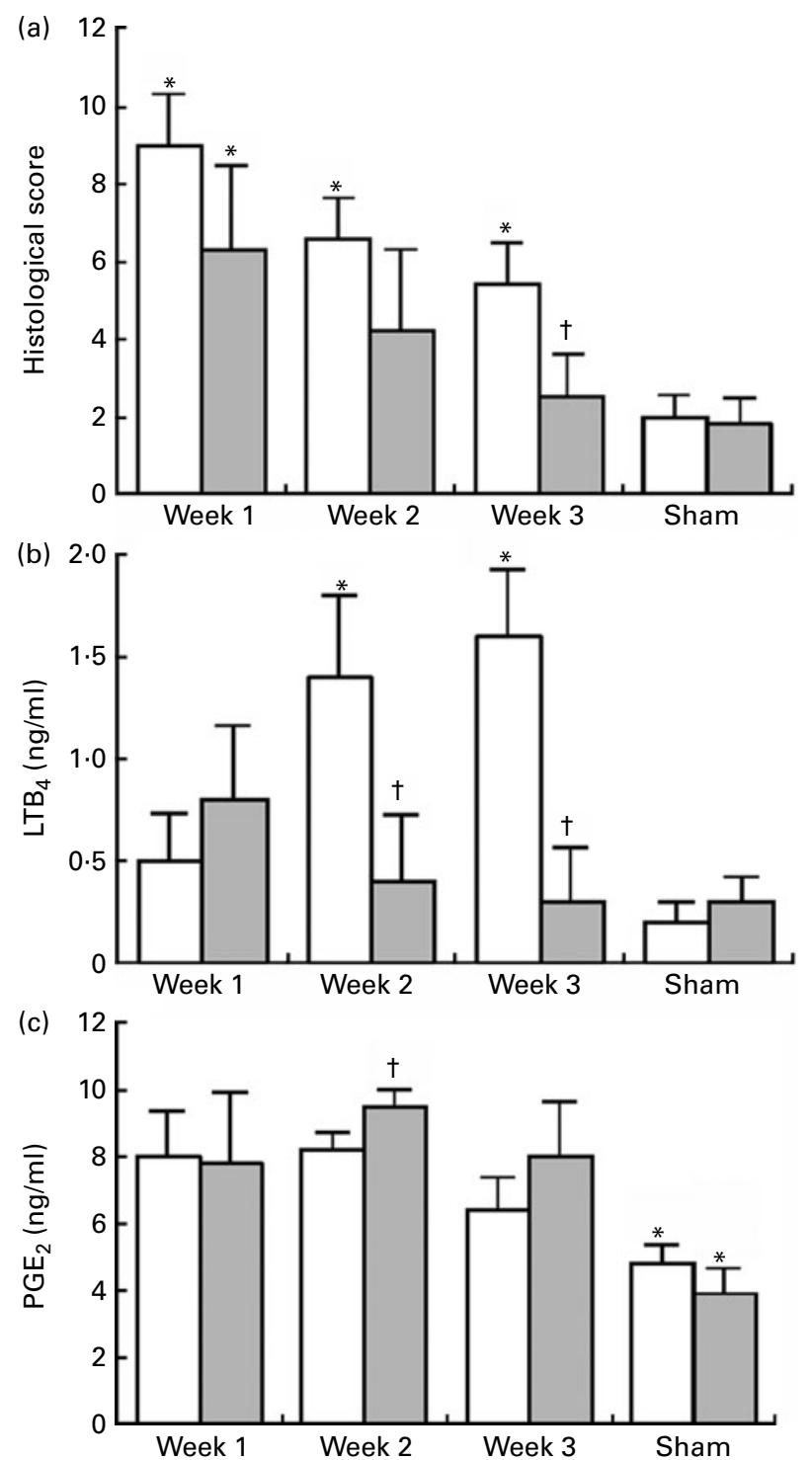

Fig. 2. (a) Histological score, (b) leukotriene $B_{4}\left(L_{T B}\right)$ and (c) $P G E_{2}$ concentration in the supernatants of $24 \mathrm{~h}$ incubated colonic explants. Values are means, with their standard errors represented by vertical bars. * Mean values were significantly different from those of sham $(P<0.05)$. † Mean values were significantly different from those of vehicle $(P<0.05)$.

colonic production of pro-inflammatory cytokines, IL-1 and IL-2, as well as the powerful chemotactic agent $\mathrm{LTB}_{4}$. AF treatment was also associated with a small but significant increase in $\mathrm{PGE}_{2}$ levels at week 2 after TNBS administration. PG have been associated with the modulation of colonic epithelial cell secretion $^{(18)}$, the development of oedema and hyperalgesia in several experimental models ${ }^{(19)}$, and $\mathrm{PGE}_{2}$ has been specifically associated with intestinal cytoprotection ${ }^{(19,20)}$. In vitro studies have shown multiple effects of $\mathrm{PGE}_{2}$ on the immune system, including inhibition of IL-2 and IFN- $\gamma$ production from human and murine T-cells ${ }^{(21)}$. Moreover, $\mathrm{PGE}_{2}$ has the capacity to inhibit the production of IL-1 in human macrophages ${ }^{(22)}$. Therefore, the increase in $\mathrm{PGE}_{2}$ production

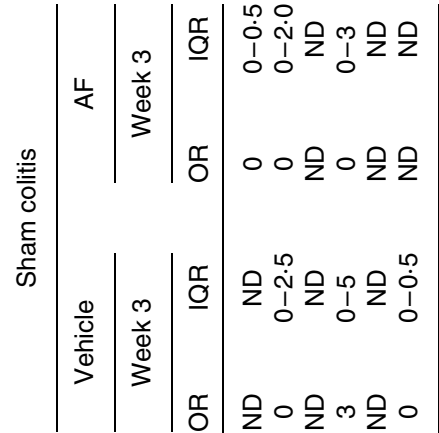

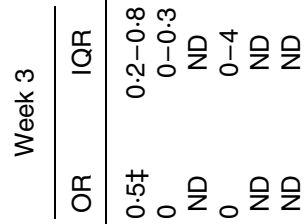

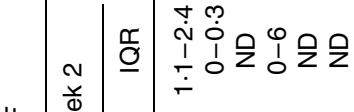

峞

3

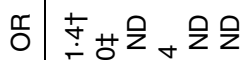

$\underline{\underline{0}}$

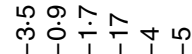

\ulcorner

$\stackrel{r}{\frac{y}{d}}$

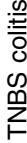

\begin{tabular}{|l}
0 \\
$\frac{0}{0}$ \\
$\frac{0}{0}$ \\
$>$
\end{tabular}

3

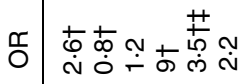

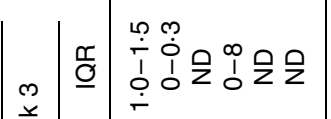

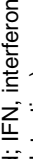

$\stackrel{\infty}{3}$

๓ᄄ口

플 
might be the initial event triggering a decrease in IL-1, IL-2, and IFN- $\gamma$ production during the late phase of TNBS colitis.

The marked differences in late $\mathrm{LTB}_{4}$ production, which decreases in AF-treated mice and increases in the vehicle-treated group, do not apparently fit with the relatively modest differences in the histological score. $\mathrm{LTB}_{4}$ is a powerful chemoattractant of neutrophils and/or lymphocytes depending on the inflammatory setting ${ }^{(23,24)}$. Mixed inflammatory infiltrate predominates in the early phases of TNBS colitis, which is replaced by a lower-degree chronic inflammation in the late phases, where the lymphocytic infiltrate predominates. One can speculate that in the late phases of TNBS colitis, the chemoattractant action of $\mathrm{LTB}_{4}$ would predominate on the lymphocytes. In fact, both clinical and in vitro studies have suggested that AF is particularly useful to modulate chronic inflammation mediated by activated $\mathrm{T}$-cells ${ }^{(4,9,10)}$. On the other hand, the absence of the correlation between TNF- $\alpha$ and myeloperoxidase activity with degree of inflammation could also be due to the fact that measurements were not performed in the earliest phases of colitis. As a whole, our results are consistent with human trials, where the beneficial effects of AF were particularly relevant in chronic long-lasting inflammatory bowel disease ${ }^{(5,9,10)}$.

In spite of the changes observed in the histological findings, we were unable to disclose any difference in cytokine production within the first week post-TNBS administration, except for IFN- $\gamma$ levels that, surprisingly, were even higher in AF-treated mice. IFN- $\gamma$ is not a disease promoter in TNBS colitis but may exert a protective action, as suggested by the fact that mice lacking IFN- $\gamma$ or its receptor are more susceptible to TNBS colitis and develop a more severe disease ${ }^{(25-27)}$. Moreover, IFN- $\boldsymbol{\gamma}$ has been proposed as a therapy for human ulcerative colitis, although its efficacy could not be proven $^{(28,29)}$. Although IFN- $\boldsymbol{\gamma}$ is considered as a pro-inflammatory cytokine associated with T-helper 1-mediated immune responses, in several experimental colitis models, IFN- $\gamma$ appears to act as an anti-inflammatory agent ${ }^{(25-27,30)}$. These studies have suggested that increased IFN- $\gamma$ production in the setting of TNBS colitis has protective properties through the induction of indoleamine-2,3-dioxigenase. This enzyme catalyses tryptophan degradation, resulting in low levels of this essential amino acid as well as in the accumulation of tryptophan metabolites, which down-regulate T-cell proliferation and induce $\mathrm{T}$-cell apoptosis ${ }^{(31,32)}$. In order to ascertain whether this was the case in the present study, we evaluated apoptosis in the colonic mucosa, and a remarkable increase in apoptosis of lamina propria lymphocytes in AF-treated mice was found. This increased apoptotic rate in AF-treated mice was associated with a decrease in intestinal inflammation, in contrast to what was observed in mice not treated with $\mathrm{AF}^{(13-15,33)}$.

In is noteworthy that some cytokines, namely IL-10, IL-5, and IL-12, were undetectable. This could be probably explained by the fact that we assessed cytokine production from week 1 onwards, whereas the increase in cytokines in this model is maximum within the first $3 \mathrm{~d}$ after TNBS administration $^{(34,35)}$. Moreover, in most studies, cytokine production has been assessed either in stimulated lymphocytes or in homogenates of the intestinal mucosa ${ }^{(35-37)}$, which could lead to a greater release of cytokines compared with their mere incubation of colonic explants.

Although AF treatment resulted in milder colonic damage in the late phases of this animal model, it was associated with a slight increase in weight loss during the first week after TNBS administration (Fig. 1), suggesting a possible worsening effect of AF in the early course of colitis. TNBS colitis is thought to be due to the binding of TNBS to host proteins, thereby eliciting a delayed-type hypersensitivity reaction to haptened selfantigens ${ }^{(28,31)}$. In this sense, it has to be taken into account that $\mathrm{AF}$ is administered as egg yolk, and AF-treated animals might develop a more severe acute colitis because of the high egg protein concentration that reaches the intestinal lumen. Protein excess in the intestinal lumen could hyperreact with TNBS producing pro-oxidative trinitrophenylated peptides and nitrosamines in the early course of TNBS colitis ${ }^{(38-40)}$. Unfortunately, as a group of animals killed before the 7th day after TNBS administration was not included, this hypothesis cannot be ascertained. Thus, studies with AF treatment starting 1 week after TNBS administration or in other experimental models, as well as studies with recombinant AF or other routes of administration, are warranted.

In conclusion, the administration of AF derived from freezedried egg yolk seems to have a significant, although moderate, therapeutic effect on the late events of acute TNBS colitis in $\mathrm{Balb} / \mathrm{c}$ mice. This beneficial effect consists of a decrease in the macroscopic and microscopic damage score, a decrease in the colonic weight:length ratio and a decrease in the local production of pro-inflammatory mediators, such as IL-1, IL-2 and $\mathrm{LTB}_{4}$. A small but significant increase in $\mathrm{PGE}_{2}$ secretion and in apoptosis counts of lamina propria lymphocytes could also contribute to this effect. All these effects should be confirmed in a model of more chronic intestinal inflammation.

\section{Acknowledgements}

The present study was financially supported by CIBERehd of the Instituto de Salud Carlos III, from the Spanish Ministry of Health, Nestlé Healthcare Nutrition and Instituto de Estudios del Huevo (Madrid, Spain). J. M. and E. C. carried out the studies and data analyses and drafted the manuscript. V. L., I. O. and E. P. carried out the samples analyses. M. A. G. and E. D. participated in the design of the study and provided essential materials. V. L. participated in its coordination and helped to draft the manuscript. All authors read and approved the final manuscript. All authors disclose any financial or personal relationships with the company or organisation sponsoring the research at the time the research was done. Such relationships may include employment, sharing in a patent, serving on an advisory board or speakers' panel, or owning shares in the company. None of the authors has any conflict of interest regarding the manuscript.

\section{References}

1. Johansson E, Lönnroth I, Lange S, et al. (1995) Molecular cloning and expression of pituitary gland protein modulating intestinal fluid secretion. J Biol Chem 270, 20615-20620. 
2. Johansson E, Jennische E, Lange S, et al. (1997) Antisecretory factor suppresses intestinal inflammation and hypersecretion. Gut 41, 642-645.

3. Kim M, Wasling P, Xiao MY, et al. (2005) Antisecretory factor modulates GABAergic transmission in the rat hippocampus. Regul Pept 129, 109-118.

4. Davidson TS \& Hickey WF (2004) Distribution and immunoregulatory properties of antisecretory factor. Lab Invest $\mathbf{8 4}$, 307-319.

5. Björck S, Bosaeus I, Ek E, et al. (2000) Food induced stimulation of the antisecretory factor can improve symptoms in human inflammatory bowel disease: a study of a concept. Gut 46, 824-829.

6. Laurenius A, Wangberg B, Lange E, et al. (2003) Antisecretory factor counteracts secretory diarrhoea of endocrine origin. Clin Nutr 22, 549-552.

7. Lange S, Bosaeus I, Jennische E, et al. (2003) Food-induced antisecretory factor activity is correlated with small bowel length in patients with intestinal resections. APMIS 111, 985-988

8. Lange S, Lönnroth I \& Martinsson K (1994) Concentrations of antisecretory factor in eggs and in chicken blood plasma. Br Poult Sci 35, 615-620.

9. Eriksson A, Shafazand M, Jennische E, et al. (2003) Effect of antisecretory factor in ulcerative colitis on histological and laborative outcome: a short period clinical trial. Scand J Gastroenterol 38, 1045-1049.

10. Eriksson A, Shafazand M, Jennische E, et al. (2003) Antisecretory factor-induced regression of Crohn's disease in a weak responder to conventional pharmacological treatment. Inflamm Bowel Dis 9, 398-400.

11. Neurath M, Fuss I \& Strober W (2000) TNBS-colitis. Int Rev Immunol 19, 51-62.

12. Morris GP, Beck PL, Herridge MS, et al. (1989) Hapteninduced model of chronic inflammation and ulceration in the rat colon. Gastroenterology 93, 795-803.

13. Sturm A \& Fiocchi C (2002) Life and death in the gut: more killing, less Crohn's. Gut 50, 148-149.

14. Santaolalla R, Mañé J, Pedrosa E, et al. (2011) Apoptosis resistance of mucosal lymphocytes and IL-10 deficiency in patients with steroid-refractory Crohn's disease. Inflamm Bowel Dis 17, 1490-1500.

15. Mañé J, Pedrosa E, Lorén V, et al. (2009) Partial replacement of dietary (n-6) fatty acids with medium-chain triglycerides decreases the incidence of spontaneous colitis in interleukin-10-deficient mice. J Nutr 139, 602-610.

16. Newmark HL (1987) Nutrient density: an important and useful tool for laboratory animal studies. Carcinogenesis $\mathbf{8}$, $871-873$

17. Mañé J, Lorén V, Pedrosa E, et al. (2009) Lactobacillus fermentum CECT 5716 prevents and reverts intestinal damage on TNBS-induced colitis in mice. Inflamm Bowel Dis 15, $1155-1163$

18. Zamuner SR, Warrier N, Buret AG, et al. (2003) Cyclooxygenase 2 mediates post-inflammatory colonic secretory and barrier dysfunction. Gut 52, 1714-1720.

19. Narumiya S (2003) Prostanoids in immunity: roles revealed by mice deficient in their receptors. Life Sci 74, 391-395.

20. Fukata M, Chen A, Klepper A, et al. (2006) Cox-2 is regulated by Toll-like receptor-4 (TLR4) signaling: role in proliferation and apoptosis in the intestine. Gastroenterology 131, $862-877$.

21. Ohara K, Kono T, Chisato N, et al. (2003) Acetic acid-derived prostaglandin-dependent colonic adaptive cytoprotection is preserved in chronic colitis: role of cyclo-oxygenase. Int J Colorectal Dis 18, 260-266.

22. Betz M \& Fox BS (1991) Prostaglandin $\mathrm{E}_{2}$ inhibits production of Th-1 lymphokines but not of Th-2 lymphokines. J Immunol 146, 108-113.

23. Yokomizo T, Kato K, Terawaki K, et al. (2000) A second leukotriene $\mathrm{B}(4)$ receptor, BLT2. A new therapeutic target in inflammation and immunological disorders. J Exp Med 192, 421-432.

24. Tager AM, Bromley SK, Medoff BD, et al. (2003) Leukotriene $\mathrm{B}_{4}$ receptor BLT1 mediates early effector T cell recruitment. Nat Immunol 4, 982-990.

25. ten Hove T, van den Blink B, Pronk I, et al. (2002) Dichotomal role of inhibition of p38 MAKP with SB 203580 in experimental colitis. Gut 50, 507-512.

26. Dohi T, Fujihashi K, Kiyono H, et al. (2000) Mice deficient in Th1- and Th2-type cytokines develop distinct forms of hapten-induced colitis. Gastroenterology 119, 724-733.

27. Dohi T, Fujihashi K, Rennert PD, et al. (1999) Hapteninduced colitis is associated with colonic patch hypertrophy and $\mathrm{T}$ helper cell 2-type responses. J Exp Med 189, 1169-1179.

28. Musch E, Andus T, Kruis W, et al. (2005) Interferon-beta-1a for the treatment of steroid-refractory ulcerative colitis: a randomized, double-blind, placebo-controlled trial. Clin Gastroenterol Hepatol 3, 581-586.

29. Pena-Rossi C, Schreiber S, Golubovic G, et al. (2008) Clinical trial: a multicentre, randomized, double-blind, placebocontrolled, dose-finding, phase II study of subcutaneous interferon-beta-la in moderately active ulcerative colitis. Aliment Pharmacol Ther 28, 758-767.

30. Gurtner GJ, Newberry RD, Schloemann SR, et al. (2003) Inhibition of indoleamine 2,3-dioxygenase augments trinitrobenzene sulfonic acid in mice. Gastroenterology $\mathbf{1 2 5}$, $1762-1773$.

31. Lee GK, Park HJ, Macleod M, et al. (2002) Tryptophan deprivation sensitizes activated $\mathrm{T}$ cells to apoptosis prior $\mathrm{T}$ cell division. Immunology 107, 452-460.

32. Fallarino F, Grohmann U, Vacca C, et al. (2002) T cell apoptosis by tryptophan catabolism. Cell Death Differ 9, 1069-1077.

33. Lügering A, Lebiedz $\mathrm{P}$, Koch S, et al. (2006) Apoptosis as a therapeutic tool in IBD? Ann N Y Acad Sci 1072, 62-77.

34. Roselli M, Finamore A, Nuccitelli S, et al. (2009) Prevention of TNBS-induced colitis by different Lactobacillus and Bifidobacterium strains is associated with an expansion of gammadeltaT and regulatory $\mathrm{T}$ cells of intestinal intraepithelial lymphocytes. Inflamm Bowel Dis 15, 1526-1536.

35. Sokol H, Pigneur B, Watterlot L, et al. (2008) Faecalibacterium prausnitzii is an anti-inflammatory commensal bacterium identified by gut microbiota analysis of Crohn disease patients. Proc Natl Acad Sci US A 105, 16731-16736.

36. Gao D, Wagner AH, Fankhaenel S, et al. (2005) CD 40 antisense oligonucleotide inhibition of trinitrobenzene sulphonic acid induced rat colitis. Gut 54, 70-77.

37. Caruso R, Sarra M, Stolfi C, et al. (2009) Interleukin-25 inhibits interleukin-12 production and Th1 cell-driven inflammation in the gut. Gastroenterology 136, 2270-2279.

38. Neurath MF, Fuss I, Kelsall BL, et al. (1996) Experimental granulomatous colitis in mice is abrogated by induction of TGF- $\beta$-mediated oral tolerance. J Exp Med 183, 2605-2616.

39. Zingarelli B, Szabó C \& Salzman AL (1999) Reduced oxidative and nitrosative damage in murine experimental colitis in absence of inducible nitric oxide synthase. Gut 45, 199-209.

40. Rachmilewitz D, Stamler JS, Karmeli F, et al. (1993) Peroxynitrite-induced rat colitis - a new model of colonic inflammation. Gastroenterology 105, 1681-1688. 